\title{
Association between Initial Fluid Choice and Subsequent In-hospital Mortality during the Resuscitation of Adults with Septic Shock
}

\author{
Karthik Raghunathan, M.D., M.P.H., Anthony Bonavia, M.D., Brian H. Nathanson, Ph.D., D.S.H.S., \\ Christopher A. Beadles, M.D., Ph.D., Andrew D. Shaw, M.B., F.R.C.A., F.F.I.C.M., F.C.C.M., \\ M. Alan Brookhart, Ph.D., Timothy E. Miller, M.B.Ch.B., F.R.C.A., Peter K. Lindenauer, M.D., M.Sc.
}

\section{ABSTRACT}

Background: Currently, guidelines recommend initial resuscitation with intravenous (IV) crystalloids during severe sepsis/septic shock. Albumin is suggested as an alternative. However, fluid mixtures are often used in practice, and it is unclear whether the specific mixture of IV fluids used impacts outcomes. The objective of this study is to test the hypothesis that the specific mixture of IV fluids used during initial resuscitation, in severe sepsis, is associated with important in-hospital outcomes.

Methods: Retrospective cohort study includes patients with severe sepsis who were resuscitated with at least 21 of crystalloids and vasopressors by hospital day 2, patients who had not undergone any major surgical procedures, and patients who had a hospital length of stay (LOS) of at least 2 days. Inverse probability weighting, propensity score matching, and hierarchical regression methods were used for risk adjustment. Patients were grouped into four exposure categories: recipients of isotonic saline alone ("Sal" exclusively), saline in combination with balanced crystalloids ("Sal + Bal"), saline in combination with colloids ("Sal + Col"), or saline in combination with balanced crystalloids and colloids ("Sal + Bal + Col"). In-hospital mortality was the primary outcome, and hospital LOS and costs per day (among survivors) were secondary outcomes.

Results: In risk-adjusted Inverse Probability Weighting analyses including 60,734 adults admitted to 360 intensive care units across the United States between January 2006 and December 2010, in-hospital mortality was intermediate in the Sal group (20.2\%), lower in the Sal + Bal group $(17.7 \%, P<0.001)$, higher in the Sal + Col group $(24.2 \%, P<0.001)$, and similar in the Sal + Bal + Col group $(19.2 \%, P=0.401)$. In pairwise propensity score-matched comparisons, the administration of balanced crystalloids by hospital day 2 was consistently associated with lower mortality, whether colloids were used (relative risk, $0.84 ; 95 \% \mathrm{CI}, 0.76$ to 0.92 ) or not (relative risk, $0.79 ; 95 \% \mathrm{CI}, 0.70$ to 0.89 ). The association between colloid use and in-hospital mortality was inconsistent, and survival was not uniformly affected, whereas LOS and costs per day were uniformly increased. Results were robust in sensitivity analyses.

Conclusions: During the initial resuscitation of adults with severe sepsis/septic shock, the types of IV fluids used may impact in-hospital mortality. When compared with the administration of isotonic saline exclusively during resuscitation, the coadministration of balanced crystalloids is associated with lower in-hospital mortality and no difference in LOS or costs per day. When colloids are coadministered, LOS and costs per day are increased without improved survival. A large randomized controlled trial evaluating crystalloid choice is warranted. Meanwhile, the use of balanced crystalloids seems reasonable. (ANesthesiology 2015; 123:00-00)

I

N US hospitals, severe sepsis and septic shock lead to more than 700,000 deaths annually. ${ }^{1,2}$ Early administration of antibiotics and resuscitation with intravenous (IV) fluids are cornerstones of initial management. ${ }^{3-5}$ Fluid choice ("which IV fluid should be used for resuscitation") remains unclear despite several large randomized controlled trials (RCTs). ${ }^{6-8}$ In these RCTs, choice was studied as a "crystalloid versus colloid" contrast, i.e., one type of crystalloid versus one type of colloid (suspended in that crystalloid), used exclusively throughout resuscitation. Hydroxyethyl starch solutions (HES), synthetic colloids, were found to increase the risk of kidney injury and death among patients with severe sepsis. ${ }^{9}$ Albumin, the human-derived colloid, was initially associated with a survival benefit, ${ }^{9-15}$ but later (in a RCT specifically studying its effects in severe sepsis) was found to have no measurable benefit or harm. ${ }^{8}$ Hence,
What We Already Know about This Topic

- During severe sepsis/septic shock, guidelines recommend prompt resuscitation with intravenous crystalloids. When large quantities are required, albumin (human-derived colloid) is suggested. However, mixtures are often used in clinical practice, and it is unknown whether and how composition of this mixture impacts outcomes.

What This Article Tells Us That Is New

- In this retrospective cohort study including 60,734 adults with septic shock (admitted across 360 intensive care units in the United States), crystalloid choice during resuscitation impacts outcomes. When compared with isotonic saline used exclusively, the administration of balanced crystalloids during initial resuscitation is associated with lower in-hospital mortality and no difference in length of stay or costs per day. When colloids are coadministered, length of stay and costs per day increase without improving survival, independent of crystalloid choice.

Brian H. Nathanson conducted data analysis; and Karthik Raghunathan, Anthony Bonavia, Brian H. Nathanson, Christopher A. Beadles, Andrew D. Shaw, M. Alan Brookhart, Timothy E. Miller, and Peter K. Lindenauer conducted the study and prepared the manuscript. All Copyright $\odot$ 2015, the American Society of Anesthesiologists, Inc. Wolters Kluwer Health, Inc. All Rights Reserved. Anesthesiology 2015; 123:00-00 
although colloids are more potent "volume expanders," they did not improve survival significantly. Current guidelines recommend resuscitation with IV crystalloids - $30 \mathrm{ml} / \mathrm{kg}$ to be administered within the first $6 \mathrm{~h}$ during severe sepsis (level of evidence 1B). ${ }^{5}$ HES is not recommended, and albumin is suggested as an alternative when substantial crystalloid volumes are used. ${ }^{5}$ In addition to differing from colloids, crystalloids differ among themselves in chloride content and strong ion difference. Yet no large RCT has studied the impact of administration of different IV fluid mixtures during severe sepsis. Providers often administer such mixtures during resuscitation, and effects of commonly used fluid mixtures need to be studied.

In practice, isotonic saline is the most commonly used resuscitation fluid. ${ }^{16}$ Alternatives, such as lactated Ringer's (LR) solution, are widely available but not commonly used during sepsis. Colloids are used frequently. ${ }^{16,17}$ A large observational study has suggested a survival benefit with the use of balanced crystalloids in severe sepsis. ${ }^{16}$ Similar benefits have also been noted during perioperative resuscitation. ${ }^{18,19}$ We conducted this study to test the hypothesis that the specific mixture of IV fluids, colloids and different types of crystalloids, used during initial resuscitation, in severe sepsis, is associated with major in-hospital outcomes. We compared in-hospital mortality after the administration of isotonic saline (used exclusively during resuscitation) versus coadministration of balanced crystalloids (such as LR) or colloids. This study design evaluates whether differences in outcome after resuscitation with different types of crystalloids is of greater clinical consequence than the "crystalloid versus colloid" dialectic.

\section{Materials and Methods}

\section{Study Population}

This study was conducted using detailed administrative and financial data collected from hospital members of the Premier healthcare alliance (Premier Inc., USA). Many details of this data set have been described previously. ${ }^{16}$ For this study, we included adult patients ( $\geq 18 \mathrm{yr})$ with a principal

authors contributed to conception and design of this study, the interpretation of data, the draft or revision of the manuscript, and final approval of the version to be published; they all agree to be accountable for all aspects of the work.

Submitted for publication February 9, 2015. Accepted for publication July 24, 2015. From the Department of Anesthesiology, Duke University Medical Center, Durham, North Carolina (K.R., T.E.M.); Anesthesiology Service, Durham Veterans Affairs Medical Center, Durham, North Carolina (K.R.); Department of Anesthesiology, Penn State Milton S. Hershey Medical Center, Hershey, Pennsylvania (A.B.); OptiStatim, LLC, Longmeadow, Massachusetts (B.H.N.); RTI International, Research Triangle Park, North Carolina (C.A.B.); Department of Anesthesiology, Vanderbilt University Medical Center, Nashville, Tennessee (A.D.S.); Department of Epidemiology, University of North Carolina at Chapel Hill, Chapel Hill, North Carolina (M.A.B.); and Department of Medicine, Center for Quality of Care Research, Baystate Medical Center, Tufts University Schoo of Medicine, Springfield, Massachusetts (P.K.L.). or a secondary diagnosis of sepsis (International Classification of Diseases, Ninth Revision, Clinical Modification codes 038, $020,790.7,117.9,112.5,112.81$, or 995.92 , as described by Martin et al.), ${ }^{20}$ a known in-hospital mortality outcome and hospital length of stay (LOS) >2 days between January 2006 and December 2010. Study entry was restricted to patients admitted urgently or emergently (i.e., nonelective admissions) to adult intensive care units, receiving vasopressors by hospital day 2. To increase specificity for a diagnosis of sepsis, entry in to the study cohort was further restricted to patients who had blood cultures drawn by hospital day 2 , had at least 3 consecutive days of IV antibiotic therapy (initiated within the first 2 hospital days), and received at least 21 of crystalloids by day 2 (i.e., patients were at least minimally resuscitated). To increase homogeneity of the study population and decrease the likelihood of confounding by differences in medical versus surgical populations, patients who underwent major surgical procedures were excluded thereby restricting the study to patients cared for mainly in a medical setting. However, we did include patients who underwent certain operative procedures (such as tracheostomy, APR-DRG 5; dialysis catheter insertion, APR-DRG 444; and/or operative treatment for infectious and/or parasitic diseases including human immunodeficiency virus, APR-DRG 710). We excluded patients transferred between facilities, because ascertainment of exposure or outcome may be uncertain. This study was exempt from full institutional review board review because deidentified administrative data were used. The Baystate Medical Center Institutional Review Board approved this study.

\section{Exposure}

Four mutually exclusive exposure categories were defined depending on the type(s) of IV fluids administered on hospital days 1 and 2: (1) patients who received isotonic saline exclusively (the "Sal" group), (2) patients who also received balanced crystalloids such as LR (the "Sal + Bal" group), (3) patients who also received colloids, either HES or albumin (the "Sal + Col" group), and (4) patients who received all three fluid types (the "Sal $+\mathrm{Bal}+\mathrm{Col}$ " group). As the initial resuscitation of adults during severe sepsis is usually conducted with containers greater than or equal to $500 \mathrm{ml}$ in volume, and as fluids administered in smaller containers ( $\leq 250 \mathrm{ml}$ in volume) are typically used to deliver medications such as vasopressors and antibiotics, we computed resuscitation fluid totals based on only fluids administered in a larger containers ( $\geq 500 \mathrm{ml}$ in volume).

In secondary analyses, we defined exposure at the hospital level rather than the patient level by grouping hospitals into quartiles based on the proportion of patients receiving specific types of fluid mixtures (isotonic saline alone or with either balanced crystalloids or colloids) at each hospital. These hospital-level analyses might overcome confounding persisting at the patient level. At the patient level, if those receiving a certain type of resuscitation fluid mixture were sicker, they might appear to have worse outcomes even after 
risk adjustment. Such patient-level confounding (by severity of illness) may be reduced in hospital-level analyses. Hospitals, comparable in patient mix, may differ in the choice of fluids made available to clinicians and reflected in the proportion of patients receiving various types of fluid mixtures. Hospital-level analyses compared risk-adjusted outcomes at the hospital level by quartile of balanced crystalloid or colloid use. We distinguished between types of colloidsalbumin versus HES - in additional analyses to ensure that differences in colloid type did not confound results.

\section{Outcome}

The primary outcome was in-hospital mortality during the index hospitalization. Secondary outcomes were hospital LOS and costs per day among survivors. To allow for a biologically plausible exposure-outcome relationship and to decrease confounding by progressive severity of illness, we restricted exposure to IV fluids received during hospital days 1 and 2. Effects on early mortality (i.e., patients who died early after admission) were included in sensitivity analyses.

\section{Confounding Variables}

Risk adjustment is necessary because we observed significant differences across exposure categories in baseline characteristics (patient and hospital demographics), patient-level comorbidities, a variety of cotreatments, and in the total fluid volume administered by hospital day 2. Differences in the volume of fluid administered within each exposure category may confound fluid type differences; hence, we controlled for the fluid volume received during the first two hospital days. We accounted for 27 well-described categories of comorbidities (as detailed by Elixhauser and classified using software provided by the Healthcare Costs and Utilization Project of the Agency for Healthcare Research and Quality_ see table 1 for a sample of the comorbidities accounted for). To further adjust for potential differences in the baseline severity of illness, we accounted for differences in the use of organ supportive therapies (such as mechanical ventilation, dialysis, and various medications including diuretics, vasopressors [both type and number], inotropes, and steroids) by hospital day 2. Differences in other treatments - such as transfusions of blood products, diagnostic/ monitoring procedures (e.g., placement of arterial and central venous catheters, echocardiography), attending physician specialties, and the total volume of crystalloid and colloid solutions received by day 2 -were also accounted for. We used random effects to minimize bias that may be introduced by hospital-specific practices. Finally, we also examined whether fluid choice changed during the study period. $^{17}$

\section{Statistical Analysis}

In univariate analyses, we represented data as frequencies and proportions for categorical variables and medians and interquartile range for continuous variables (using chisquare or $t$ tests, respectively). Given the significant potential for observed and unobserved confounding inherent in our nonrandomized study design, we used different multivariate

Table 1. Baseline Prevalence of Selected Significant Patient and Hospital Demographics, Comorbidities, and Cotreatments across the Four Mutually Exclusive Exposure Categories

\begin{tabular}{|c|c|c|c|c|}
\hline & $\begin{array}{c}\text { Saline } \\
(\mathrm{N}=44,347)\end{array}$ & $\begin{array}{l}\mathrm{Sal}+\mathrm{Bal} \\
(\mathrm{N}=3,651)\end{array}$ & $\begin{array}{c}\text { Sal + Col } \\
(N=11,038)\end{array}$ & $\begin{array}{l}\mathrm{Sal}+\mathrm{Bal}+\mathrm{Col} \\
\quad(\mathrm{N}=1,698)\end{array}$ \\
\hline Age (yr) & $68(56-79)$ & $65(53-76)$ & $67(56-78)$ & $65(53-77)$ \\
\hline Male & 50.51 & 49.38 & 51.30 & 47.53 \\
\hline Congestive heart failure & 32.97 & 23.66 & 34.05 & 23.97 \\
\hline Hypertension & 31.94 & 35.11 & 26.53 & 33.27 \\
\hline Chronic pulmonary disease & 32.34 & 24.95 & 29.40 & 25.91 \\
\hline Chronic kidney disease & 6.02 & 4.40 & 6.61 & 4.07 \\
\hline AKI on admission & 33.12 & 32.68 & 36.34 & 31.16 \\
\hline Liver disease & 5.77 & 6.16 & 11.22 & 8.42 \\
\hline Deficiency anemia & 40.42 & 36.04 & 43.24 & 38.81 \\
\hline Total crystalloid by day 2 & $5,000(3,500-8,000)$ & $7,500(5,000-10,500)$ & $5,500(3,500-8,000)$ & $8,500(6,000-12,500)$ \\
\hline Mechanical ventilation by day 2 & 40.41 & 48.32 & 50.52 & 68.02 \\
\hline Two or more vasopressors by day 2 & 32.59 & 39.09 & 43.05 & 55.71 \\
\hline Sodium bicarbonate by day 2 & 26.07 & 27.88 & 41.34 & 45.94 \\
\hline Hydrocortisone by day 2 & 22.00 & 24.35 & 28.35 & 30.98 \\
\hline Total parenteral nutrition by day 2 & 1.56 & 3.67 & 2.51 & 7.24 \\
\hline CVP monitor by day 2 & 51.10 & 57.85 & 57.85 & 66.67 \\
\hline Arterial line by day 2 & 11.86 & 17.89 & 16.49 & 26.09 \\
\hline $\begin{array}{l}\text { Erythrocyte/whole blood transfusion } \\
\text { by day } 2\end{array}$ & 19.99 & 24.62 & 28.56 & 40.93 \\
\hline Diuretics by day 2 & 23.06 & 18.65 & 29.65 & 24.79 \\
\hline CT scan pelvis/abdominal by day 2 & 22.90 & 41.25 & 29.94 & 53.59 \\
\hline Tracheotomy by day 2 & 3.12 & 4.74 & 3.86 & 7.07 \\
\hline
\end{tabular}

$\mathrm{AKI}=$ acute kidney injury; Bal = balanced crystalloids; Col = colloids; $\mathrm{CT}=$ computed tomography; CVP = central venous pressure; Sal = saline . 
methods for risk adjustment. We used inverse probability weighting (IPW), propensity score matching (PSM), and hierarchical logistic regression methods. Although these methods estimate different effects (average treatment effect $v s$. the average effect of treatment among those treated), consistency in the direction and magnitude of different effect estimates would increase confidence in the validity of results in different patient populations.

In IPW analyses, a "pseudo-population" is assembled from the original study cohort but weighting outcomes inversely to the probability of treatment, thereby controlling for confounding by treatment indication. In contrast to augmented IPW analyses (where the entire population is represented and the average treatment effect is estimated), when comparing outcomes in the PSM-matched cohort, we were estimating the average effect of treatment among those treated, whom we could match with those untreated on all measured covariates. This does not estimate the same (average treatment) effect as in IPW analyses because only those patients who can be matched are included in analyses. PSM methods estimate the average effect of treatment in the treated and matched patients.

To calculate propensity scores, we used a hierarchical mixed-effects logistic regression models with patient and hospital-level covariates predicting the receipt of balanced crystalloids ( $v s$. not) and colloids ( $v s$. not). This hierarchical approach adjusted for clustering of effects at the hospital level. We then matched patients based on the propensity scores using a 5:1 greedy match algorithm. Patients most similar to each other in propensities were paired, thereby assembling a group of patients similar in all measurable aspects and differing only in the actual treatment received (balanced crystalloids or colloids). Multiple pairwise comparisons were performed contrasting the four exposure groups that differed in the receipt of balanced crystalloids versus not (with and without colloids) and colloids versus not (with and without balanced crystalloids). In addition to IPW and PSM analyses, we also estimated treatment effects in a hierarchical multivariate logistic regression model with in-hospital mortality as the dependent variable (outcome) and with all observed confounders and the four exposure (treatment) groups as independent categorical variables. Finally, we examined the outcome differences based on the hospital-level exposure with hospitals grouped into quartiles depending on the proportion of patients receiving balanced fluids and/or colloids at the hospital level. By comparing hospitals with higher versus lower proportions of patients receiving colloids and/or balanced crystalloids, we controlled for patient-level confounding (but may have introduced hospital-level confounding).

\section{Sensitivity Analyses}

By using the methods described by Lin et al., ${ }^{21}$ we identified the magnitude and direction that a hypothetical unmeasured confounder would need to have to change our observed associations. We also repeated analyses including patients with a
LOS less than 2 days. Early mortality (e.g., on day 1) may serve as a "control outcome." For instance, it is possible that sicker patients may receive colloids during initial resuscitation (when more "potent" volume expansion was desired), and this underlying severity of illness rather than fluid choice alone may explain the increased risk of death. If this were occurring, we would observe a stronger association between colloid use and mortality on day 1 (i.e., we would observe differences in the association between initial fluid choice and early $v$ s. late mortality outcomes).

\section{Results}

All analyses were performed using Stata/MP 13.1 (StataCorp LP, USA). Figure 1 shows the final study cohort including 60,734 adult patients admitted with a diagnosis of sepsis to 1 of 360 intensive care units (by hospital day 2) around the United States. A majority of these patients received only isotonic saline exclusively during hospital days 1 and 2 (Sal group: $73 \%, \mathrm{n}=44,347)$. Many patients also received colloids (Sal + Col group: $18 \%, \mathrm{n}=11,038$ ), a minority received balanced crystalloids (Sal + Bal group: $6 \%, \mathrm{n}=3,651)$, and only 3\% received all three fluid types ( $\mathrm{Sal}+\mathrm{Bal}+\mathrm{Col}$ group, $\mathrm{n}=1,698)$. Albumin was the predominant colloid used during resuscitation for severe sepsis in the United States, and LR (rather than Plasma-Lyte [Baxter Healthcare, USA], Normosol [Hospira, USA]) was the predominant balanced crystalloid. Selected univariate differences are shown in table 1 to highlight baseline differences across the four exposure categories and demonstrate that multivariate adjustment was necessary to control for confounding.

When compared with the Sal group, patients in the Bal + Sal group were younger and less likely to have heart or chronic renal failure, hypertension or diabetes with complications, and anemia but were more likely to receive mechanical ventilation, invasive monitoring, steroids, multiple vasopressors, and larger crystalloid volumes. Hence, there was no consistent difference in the severity of illness between Sal versus Sal + Bal groups. Conversely, patients in the Sal + Col group were more likely to have heart or renal or liver failure, hypertension or diabetes with complications, and anemia and also more likely to receive mechanical ventilation, dialysis, invasive monitoring, steroids, and multiple vasopressors. Hence, severity of illness was consistently higher among colloid recipients. The total volume of crystalloids received during the first 2 days varied across the groups. Those receiving balanced crystalloids typically received more crystalloids overall. This difference in fluid volume (across the fluid types being compared) was accounted for in all our models (IPW, PSM, and multivariate hierarchical regression). We confirmed that our decision to exclude fluid administered in small containers ( $\leq 250 \mathrm{ml}$ volume) did not introduce significant differences in volume by noting that on average, the total crystalloid volume received in small containers was approximately less than 11 by day 2 ( $v s .>51$ delivered in containers $\geq 500 \mathrm{ml}$ in size). 


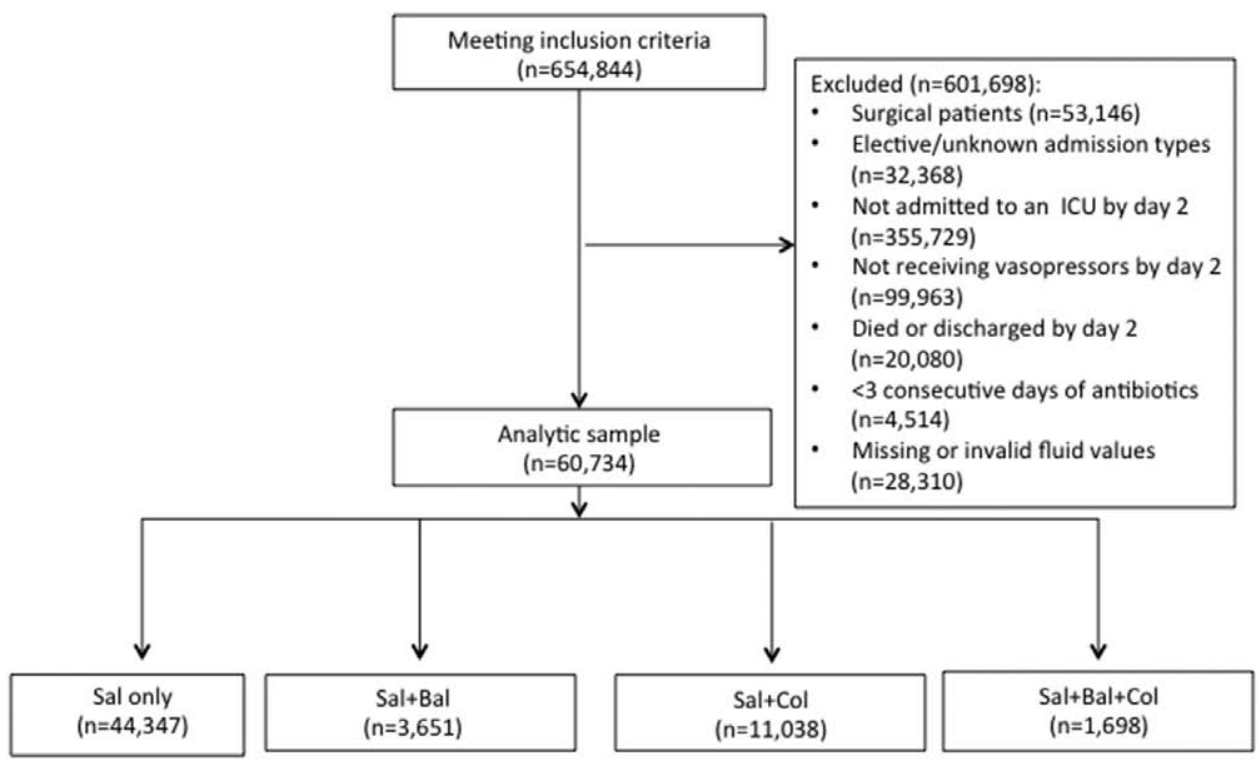

Fig. 1. The study cohort. A homogeneous group of "medical" patients admitted emergently or urgently with a diagnosis of sepsis; receiving care in an ICU and vasopressors by day 2; surviving through hospital days 1 and 2; and receiving at least 3 consecutive days of antibiotics were included. Patients with missing values for exposure, outcome, or covariates were excluded. $\mathrm{Bal}=$ balanced crystalloids; $\mathrm{Col}=$ colloids; $\mathrm{ICU}=$ intensive care unit; Sal $=$ saline .

\section{Multivariable IPW, Hierarchical Regression, and PSM Analyses}

In IPW analyses (table 2), risk-adjusted in-hospital mortality was intermediate in the Sal group (20.19\%). In comparison, absolute in-hospital mortality was lower in the Sal $+\mathrm{Bal}$ group (17.69\%, $P<0.001)$, higher in the $\mathrm{Sal}+\mathrm{Col}$ group $(24.16 \%, P<0.001)$, and equivalent in the $\mathrm{Sal}+\mathrm{Bal}+\mathrm{Col}$ group (19.23\%, $P=0.401)$. The hierarchical logistic regression model produced similar results (table 2). This model, including patient and hospital demographics, comorbidities, cotreatments, fluid volume, and fluid type as independent variable with in-hospital mortality as the dependent variable, had a c-statistic (area under receiver operating characteristic curve) of 0.763 (95\% CI, 0.758 to 0.767 ), which is consistent with sufficiently accurate risk adjustment so as to provide reasonable protection against confounding. ${ }^{22}$
In pairwise PSM comparisons, the receipt of balanced crystalloids by hospital day 2 was consistently associated with lower mortality whether colloids were used (relative risk, $0.84 ; 95 \% \mathrm{CI}, 0.76$ to 0.92 ) or not (relative risk, $0.78 ; 95 \% \mathrm{CI}, 0.70$ to 0.89 ; fig. 2). In contrast, the receipt of colloids was associated with either no effect on mortality (when balanced crystalloids were coadministered, relative risk of mortality included the null) or increased mortality (when balanced crystalloids were not administered). Observed "colloid effects" remained unchanged with analyses restricted to albumin (i.e., excluding HES). Secondary outcomes, hospital LOS and costs per day among survivors, were comparable among balanced crystalloids recipients versus nonrecipients. However, both hospital LOS and costs per day were higher among colloid recipients than nonrecipients.

Table 2. Associations between Fluid Choice and In-hospital Mortality

\begin{tabular}{|c|c|c|c|c|}
\hline Absolute Mortality & Sal & $\mathrm{Bal}+\mathrm{Sal}$ & $\mathrm{Sal}+\mathrm{Col}$ & $\mathrm{Bal}+\mathrm{Sal}+\mathrm{Col}$ \\
\hline Unadjusted estimate & $20.25 \%$ & $17.64 \%$ * & $29.94 \% *$ & $25.15 \%$ * \\
\hline $\begin{array}{l}\text { IPW-based adjustment } \\
(95 \% \mathrm{Cl})\end{array}$ & 20.19\% (19.49-20.89) & $\begin{array}{l}17.69 \% \%^{*}(16.40-18.88) \\
P<0.001\end{array}$ & $\begin{array}{l}24.16 \% *(22.94-25.38) \\
\quad P<0.001\end{array}$ & $\begin{array}{l}19.23 \%(17.03-21.44) \\
P=0.401\end{array}$ \\
\hline $\begin{array}{l}\text { Multilevel logistic regres- } \\
\text { sion-based adjustment } \\
(95 \% \mathrm{Cl})\end{array}$ & $21.35 \%(20.55-20.14)$ & $\begin{array}{l}18.83 \%^{*}(17.42-20.24) \\
\quad P<0.001\end{array}$ & $\begin{array}{l}25.36 \% *(24.25-26.47) \\
\quad P<0.001\end{array}$ & $\begin{array}{l}19.97 \%(18.12-21.82) \\
\quad P=0.138\end{array}$ \\
\hline Relative Mortality Risk & Bal vs. Sal (without Col) & Bal vs. Sal (with Col) & Col vs. Sal (without Bal) & Col vs. Sal (with Bal) \\
\hline $\begin{array}{l}\text { Comparisons of PSM } \\
\text { cohorts, greedy } \\
\text { matched }\end{array}$ & $\begin{array}{c}0.84^{\star}(0.76-0.92) \\
P<0.001\end{array}$ & $\begin{array}{l}0.79^{\star}(0.70-0.89) \\
\quad P<0.001\end{array}$ & $\begin{array}{l}1.14^{*}(1.08-1.19) \\
\quad P<0.001\end{array}$ & $\begin{array}{l}0.99(0.86-1.15) \\
P=0.920\end{array}$ \\
\hline $\begin{array}{l}\text { Comparisons of IPW } \\
\text { cohorts }\end{array}$ & $\begin{array}{c}0.87^{\star}(0.81-0.93) \\
P<0.001\end{array}$ & $\begin{array}{l}0.82^{\star}(0.73-0.90) \\
P<0.001\end{array}$ & $\begin{array}{l}1.13^{*}(1.09-1.16) \\
P<0.001\end{array}$ & $\begin{array}{c}1.09(0.98-1.21) \\
P=0.119\end{array}$ \\
\hline
\end{tabular}

Fluid choice was defined based on the day-level charges on the first two hospital days. In-hospital mortality after hospital day 2 was the primary outcome. ${ }^{*}$ Values are significantly different than the saline referent category at $P<0.001 . P$ values have isotonic saline exclusively as the referent category.

$\mathrm{Bal}=$ balanced crystalloids; $\mathrm{Col}=$ colloids; IPW = inverse probability weighting; $\mathrm{PSM}=$ propensity score matching; Sal = saline. 




Fig. 2. Relative risk in pairwise comparisons. Here relative risk less than 1 implies improved survival to discharge, whereas more than 1 implies increased risk of death. With or without colloids, the receipt of balanced crystalloids is consistently associated with better survival $(95 \% \mathrm{Cl},<1$ in multiple risk-adjusted analyses). The impact of colloids on mortality is not consistent $(95 \% \mathrm{Cl}$ includes 1 for certain estimates). Bal = balanced crystalloids; Col = colloids; Sal = saline.

\section{Sensitivity Analyses}

In sensitivity analyses using methods described by Lin et al. ${ }^{21}$ we observed that a strong, unevenly distributed confounder would negate the observed association between colloid use and increased mortality but not between balanced crystalloid use and decreased mortality. In additional sensitivity analyses including early outcomes, we observed inconsistent results for "colloid versus not" analyses but not for the "balanced crystalloid versus not" analyses. In other words, balanced crystalloids were associated with lower early and late mortality, whereas colloids were associated with lower early mortality and higher late mortality. In hospital-level analyses, on average, most hospitals treated less than $10 \%$ of patients with balanced crystalloids. Conversely, the mean colloid treatment rate was $21.0 \%$, ranging from 0 to $7.6 \%$ (at hospitals in the lowest quartile) through more than $29.9 \%$ (quartile 4). After risk adjustment, in-hospital mortality was highest at hospitals where the proportion of patients receiving balanced crystalloids was the lowest (quartile 1), and as this proportion increased (quartile 2 to 4 ), the risk of mortality decreased. There was no such trend at the hospital level with increasing proportions of patients receiving colloids (fig. 3).

\section{Discussion}

We observed an association among fluid choices during the initial resuscitation of adults with severe sepsis or septic shock and subsequent in-hospital mortality. When compared with patients who received isotonic saline exclusively, patients who had also received balanced crystalloids were more likely to survive to discharge (even when they received colloids) with no difference in the hospital LOS or costs per day. Initial therapy with colloids was associated with either increased mortality (when balanced crystalloids were not coadministered) or no difference in survival (when balanced crystalloids were coadministered). Hospital LOS and costs per day were higher when colloids were used. Thus, the association between crystalloid type and survival was more consistent and significant than the "crystalloid versus colloid" distinction.

Our results are concordant with RCTs assessing fluid choice during resuscitation in sepsis. ${ }^{6-8}$ Similar to these RCTs, we found either no difference in survival or increased risk of mortality with colloid therapy. Sensitivity analyses suggest that the overall effect of colloids tend toward no benefit or harm. In contrast, different types of crystalloids have not been simultaneously compared with each other and with different types of colloids in severe sepsis. Effects of different fluid mixtures have not been studied either. ${ }^{16,18,19}$ Adverse outcomes have been reported with the use of isotonic saline in preclinical studies, ${ }^{23,24}$ among healthy human volunteers, ${ }^{25,26}$ in large observational studies, ${ }^{18,27,28}$ and in small RCTs. ${ }^{19,29-32}$ Studies comparing chloride-liberal IV fluids versus restricted crystalloid solutions (among critically ill patients) suggest potential for adverse outcomes associated with supraphysiologic chloride levels. ${ }^{24,32,33}$ 


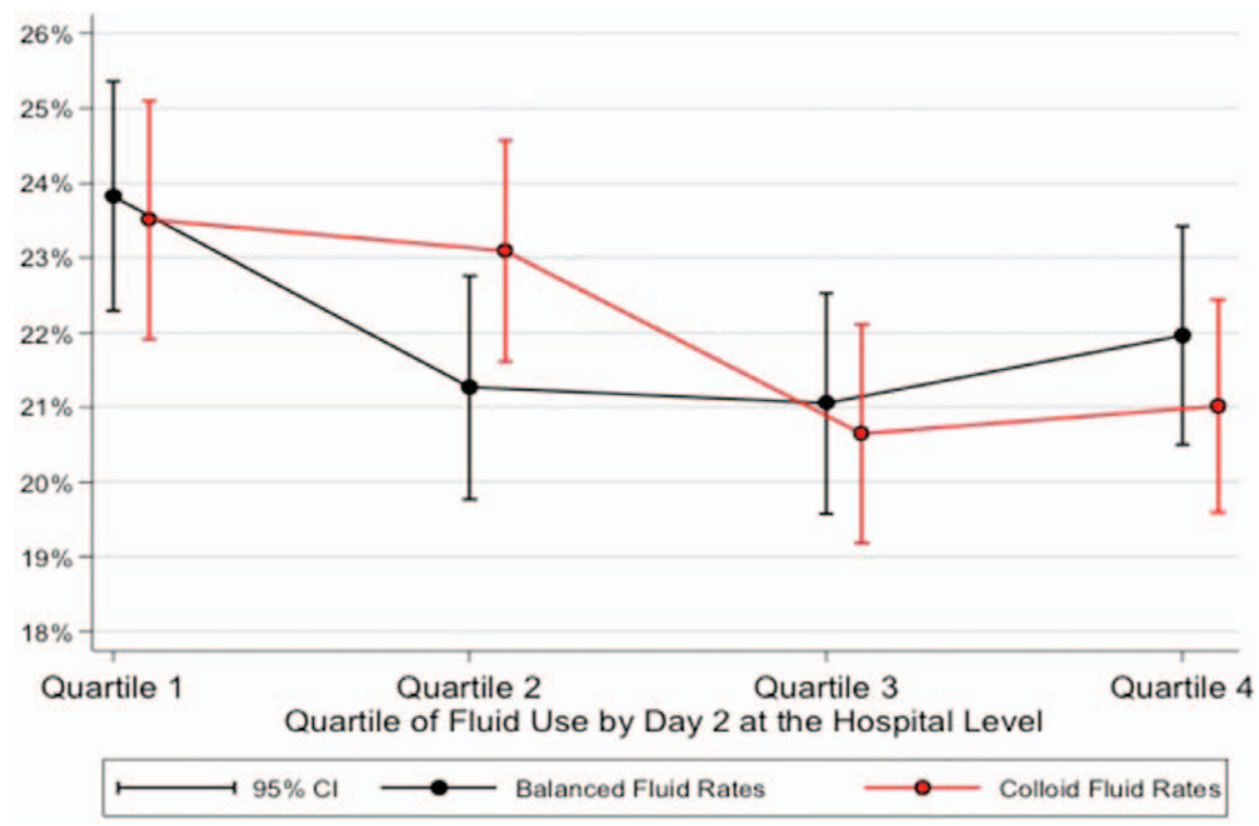

Fig. 3. Mortality versus fluid choice: by quartile of choice at the hospital level. At the hospital level, as the proportion of patients receiving balanced fluids or colloids increased (from quartiles 1 through 4), mortality decreased. The trend was significant for balanced crystalloids but not for colloids (after adjusting for all hospital-level differences in patient mix and hospital characteristics such as teaching status, bed size, and geographic location).

\section{Implications}

Improved survival with balanced crystalloids is noteworthy because LR is widely available and inexpensive, but rarely used by most clinicians currently caring for patients with severe sepsis in the United States. Saline remains the preferred choice despite the lack of RCTs showing benefits with this specific fluid. Although the mortality benefit with balanced crystalloids may be modest, public health implications may be significant because IV fluid therapy is nearly universal during sepsis. A transition from isotonic saline to LR (or other balanced crystalloids) as the default fluid choice during resuscitation in severe sepsis may translate into a measurable improvement in survival at the population level. Our findings regarding colloid therapy (concordant with RCTs) suggest that continued use may not be cost-effective. We draw attention to the direction of "fluid debates." The future discussion regarding fluid choice may not be "crystalloids versus colloids." RCTs may need to evaluate differences across crystalloids based on chloride content and/or strong ion difference.

\section{Strengths and Limitations}

We evaluated a large homogeneous cohort of patients with "medical sepsis," multiple institutions, 5 yr of data, used detailed day-level billing information for risk adjustment, and exposure allocation, and studied a reliable and clinically important outcome. We observed consistent effects independent of the analytic methods used making our findings-regarding the potential benefits of the balanced crystalloids - noteworthy. We conducted several sensitivity analyses in which findings regarding benefits from balanced crystalloid therapy were confirmed but harm from colloid therapy was not. Augmented IPW analyses estimate average treatment effects (what might happen if one treatment was replaced by another in the entire population). PSMbased comparisons include only those patients who could be matched, and thus, observed associations may apply only to the types of patients who could be matched, estimating average treatment effects among the treated.

RCTs typically allocate patients to the use of one type of fluid versus another exclusively, ${ }^{6-8}$ but this is uncommon in clinical practice (over a quarter of patients in our study received a mixture of fluids). Our exposure definition does not allocate patients to diametrically different fluid types; rather we study the effects of fluid mixtures. Patients receiving other fluids than just isotonic saline ( $27 \%$ of the cohort) may remain systematically different from saline recipients (73\% of the cohort) such that residual confounding cannot be ruled out despite rigorous risk adjustment. Clinicians were likely to choose colloids for more severely ill patients. Risk-adjusted estimates of harm with colloid therapy were lower than unadjusted estimates (table 2). Therefore, our risk-adjustment methods did offer some protection against confounding, ${ }^{23}$ but residual confounding seems likely in patient-level analyses involving colloids because sensitivity analyses suggested neither consistent harm from colloids (in hospital-level comparisons) nor consistent benefit from colloids (with only early mortality as the outcome). In contrast, a smaller proportion of the study population received balanced crystalloids, but these patients were not consistently less or more severely ill. Thus, the conclusion that balanced crystalloids were associated with better outcomes is subject to less residual confounding than the colloid 
results. Furthermore, charges for crystalloids as group (LR $v s$. saline) are similar and are significantly lower than for colloids, reducing the likelihood that bias from differential coding of charges influence the crystalloid type associations we observed. The biologic mechanisms for a survival advantage with balanced crystalloids remain unclear from these data, because we do not have laboratory or physiologic data to support a specific mechanism for benefits. Internists, hospitalists, and intensivists - rather than anesthesiologistscared for most patients in our study. However, this may be a reflection of practice patterns in the United States. Anesthetists remain responsible for the provision of intensive care (including patients with severe sepsis) in much of the world. It is unclear whether patients with severe sepsis managed by intensivists with core training in internal medicine rather than anesthesiology would have different outcomes. ${ }^{34}$

\section{Conclusions}

We observed a consistent association between the type of crystalloid used during the initial resuscitation of adults with severe sepsis or septic shock and subsequent in-hospital mortality. The use of colloids was associated with higher LOS and costs per day with no consistent effect on survival. A large RCT evaluating crystalloid choice is warranted. ${ }^{35}$ Meanwhile, the use of inexpensive and effective balanced crystalloids may be reasonable during initial resuscitation in severe sepsis.

\section{Acknowledgments}

This study was supported by the Anesthesia Patient Safety Foundation (Indianapolis, Indiana) in the form of the Anesthesia Patient Safety Foundation/American Society of Anesthesiologists Endowed Research Award in 2014 (to Dr. Raghunathan) and by the Department of Anesthesiology, Duke University Medical Center (Durham, North Carolina) in the form of the DREAM Innovation grant in 2013 (to Dr. Raghunathan). All authors take responsibility for the integrity of the data and the accuracy of the data analysis.

\section{Competing Interests}

Dr. Raghunathan received an Investigator-Initiated Trial Award in April 2014 from Baxter Healthcare (Washington, D.C.) and does not receive any consulting fees and is not a member of the Speakers Bureau; Dr. Shaw has received consulting fees from Baxter Healthcare and Grifols (Barcelona, Spain); Dr. Miller has received consulting fees from Edwards Lifesciences (Irvine, California) and Grifols; and Dr. Brookhart has received support from the National Institutes of Health (Bethesda, Maryland), Amgen (Thousand Oaks, California), Merck (Kenilworth, New Jersey), and RxAnte (Arlington, Virginia). The remaining authors declare no competing interests.

\section{Correspondence}

Address correspondence to Dr. Raghunathan: Department of Anesthesiology, Duke University Medical Center/Durham VA Medical Center, DUMC 3094, Durham, North Carolina 27710. karthik.raghunathan@duke.edu. Information on purchasing reprints may be found at www.anesthesiology.org or on the masthead page at the beginning of this issue. Anesthesiology's articles are made freely accessible to all readers, for personal use only, 6 months from the cover date of the issue.

\section{References}

1. Mayr FB, Yende S, Angus DC: Epidemiology of severe sepsis. Virulence 2014; 5:4-11

2. Lagu T, Rothberg MB, Shieh MS, Pekow PS, Steingrub JS, Lindenauer PK: Hospitalizations, costs, and outcomes of severe sepsis in the United States 2003 to 2007. Crit Care Med 2012; 40:754-61

3. Levy MM, Fink MP, Marshall JC, Abraham E, Angus D, Cook D, Cohen J, Opal SM, Vincent JL, Ramsay G; SCCM/ ESICM/ACCP/ATS/SIS: 2001 SCCM/ESICM/ACCP/ATS/SIS International Sepsis Definitions Conference. Crit Care Med 2003; 31:1250-6

4. Myburgh JA, Mythen MG: Resuscitation fluids. N Engl J Med 2013; 369:1243-51

5. Dellinger RP, Levy MM, Rhodes A, Annane D, Gerlach H, Opal SM, Sevransky JE, Sprung CL, Douglas IS, Jaeschke R, Osborn TM, Nunnally ME, Townsend SR, Reinhart K, Kleinpell RM, Angus DC, Deutschman CS, Machado FR, Rubenfeld GD, Webb S, Beale RJ, Vincent JL, Moreno R; Surviving Sepsis Campaign Guidelines Committee including The Pediatric Subgroup: Surviving Sepsis Campaign: International guidelines for management of severe sepsis and septic shock, 2012. Intensive Care Med 2013; 39:165-228

6. Brunkhorst FM, Engel C, Bloos F, Meier-Hellmann A, Ragaller M, Weiler N, Moerer O, Gruendling M, Oppert M, Grond S Olthoff D, Jaschinski U, John S, Rossaint R, Welte T, Schaefer M, Kern P, Kuhnt E, Kiehntopf M, Hartog C, Natanson C, Loeffler M, Reinhart K; German Competence Network Sepsis (SepNet): Intensive insulin therapy and pentastarch resuscitation in severe sepsis. N Engl J Med 2008; 358:125-39

7. Perner A, Haase N, Guttormsen AB, Tenhunen J, Klemenzson G, Åneman A, Madsen KR, Møller MH, Elkjær JM, Poulsen LM, Bendtsen A, Winding R, Steensen M, Berezowicz P, SøeJensen P, Bestle M, Strand K, Wiis J, White JO, Thornberg KJ, Quist L, Nielsen J, Andersen LH, Holst LB, Thormar K, Kjældgaard AL, Fabritius ML, Mondrup F, Pott FC, Møller TP, Winkel P, Wetterslev J; 6S Trial Group; Scandinavian Critical Care Trials Group: Hydroxyethyl starch 130/0.42 versus Ringer's acetate in severe sepsis. N Engl J Med 2012; 367:124-34

8. Caironi P, Tognoni G, Masson S, Fumagalli R, Pesenti A, Romero M, Fanizza C, Caspani L, Faenza S, Grasselli G, Iapichino G, Antonelli M, Parrini V, Fiore G, Latini R, Gattinoni L; ALBIOS Study Investigators: Albumin replacement in patients with severe sepsis or septic shock. N Engl J Med 2014; 370:1412-21

9. Haase N, Perner A, Hennings LI, Siegemund M, Lauridsen B, Wetterslev M, Wetterslev J: Hydroxyethyl starch 130/0.380.45 versus crystalloid or albumin in patients with sepsis: Systematic review with meta-analysis and trial sequential analysis. BMJ 2013; 346:f839

10. Bansal M, Farrugia A, Balboni S, Martin G: Relative survival benefit and morbidity with fluids in severe sepsis-A network meta-analysis of alternative therapies. Curr Drug Saf 2013; 8:236-45

11. Myburgh JA, Finfer S, Bellomo R, Billot L, Cass A, Gattas D, Glass P, Lipman J, Liu B, McArthur C, McGuinness S, Rajbhandari D, Taylor CB, Webb SA; CHEST Investigators; Australian and New Zealand Intensive Care Society Clinical Trials Group: Hydroxyethyl starch or saline for fluid resuscitation in intensive care. N Engl J Med 2012; 367:1901-11

12. Finfer S, Bellomo R, Boyce N, French J, Myburgh J, Norton $\mathrm{R}$; SAFE Study Investigators: A comparison of albumin and 
saline for fluid resuscitation in the intensive care unit. $\mathrm{N}$ Engl J Med 2004; 350:2247-56

13. McIntyre LA, Fergusson D, Cook DJ, Rankin N, Dhingra V, Granton J, Magder S, Stiell I, Taljaard M, Hebert PC; Canadian Critical Care Trials Group: Fluid resuscitation in the management of early septic shock (FINESS): A randomized controlled feasibility trial. Can J Anaesth 2008; 55:819-26

14. Guidet B, Martinet $\mathrm{O}$, Boulain T, Philippart F, Poussel JF, Maizel J, Forceville X, Feissel M, Hasselmann M, Heininger A, Van Aken H: Assessment of hemodynamic efficacy and safety of $6 \%$ hydroxyethylstarch $130 / 0.4 v s .0 .9 \% \mathrm{NaCl}$ fluid replacement in patients with severe sepsis: The CRYSTMAS study. Crit Care 2012; 16:R94

15. Maitland K, Kiguli S, Opoka RO, Engoru C, Olupot-Olupot P, Akech SO, Nyeko R, Mtove G, Reyburn H, Lang T, Brent B, Evans JA, Tibenderana JK, Crawley J, Russell EC, Levin M, Babiker AG, Gibb DM; FEAST Trial Group: Mortality after fluid bolus in African children with severe infection. N Engl J Med 2011; 364:2483-95

16. Raghunathan K, Shaw A, Nathanson B, Stürmer T, Brookhart A, Stefan MS, Setoguchi S, Beadles C, Lindenauer PK: Association between the choice of IV crystalloid and in-hospital mortality among critically ill adults with sepsis*. Crit Care Med 2014; 42:1585-91

17. Raghunathan K, Beadles C, Nathanson BH, Lindenauer PK The authors reply. Crit Care Med 2015; 43:e27-8

18. Shaw AD, Bagshaw SM, Goldstein SL, Scherer LA, Duan M, Schermer CR, Kellum JA: Major complications, mortality, and resource utilization after open abdominal surgery: 0.9\% saline compared to Plasma-Lyte. Ann Surg 2012; 255:821-9

19. Burdett E, Dushianthan A, Bennett-Guerrero E, Cro S, Gan TJ, Grocott MP, James MF, Mythen MG, O'Malley CM, Roche AM, Rowan K: Perioperative buffered versus non-buffered fluid administration for surgery in adults. Cochrane Database Syst Rev 2012; 12:CD004089

20. Martin GS, Mannino DM, Eaton S, Moss M: The epidemiology of sepsis in the United States from 1979 through 2000 N Engl J Med 2003; 348:1546-54

21. Lin DY, Psaty BM, Kronmal RA: Assessing the sensitivity of regression results to unmeasured confounders in observational studies. Biometrics 1998; 54:948-63

22. Sjoding MW, Luo K, Miller MA, Iwashyna TJ: When do confounding by indication and inadequate risk adjustment bias critical care studies? A simulation study. Crit Care 2015; 19:195

23. Wilcox CS: Regulation of renal blood flow by plasma chloride. J Clin Invest 1983; 71:726-35

24. Bullivant EM, Wilcox CS, Welch WJ: Intrarenal vasoconstriction during hyperchloremia: Role of thromboxane. Am J Physiol 1989; 256(1 pt 2):F152-7
25. Chowdhury AH, Cox EF, Francis ST, Lobo DN: A randomized, controlled, double-blind crossover study on the effects of 1-L infusions of $6 \%$ hydroxyethyl starch suspended in $0.9 \%$ saline (Voluven) and a balanced solution (Plasma Volume Redibag) on blood volume, renal blood flow velocity, and renal cortical tissue perfusion in healthy volunteers. Ann Surg 2013; 259:881-7

26. Lobo DN, Stanga Z, Aloysius MM, Wicks C, Nunes QM, Ingram KL, Risch L, Allison SP: Effect of volume loading with 1 liter intravenous infusions of $0.9 \%$ saline, $4 \%$ succinylated gelatine (Gelofusine) and 6\% hydroxyethyl starch (Voluven) on blood volume and endocrine responses: A randomized, three-way crossover study in healthy volunteers. Crit Care Med 2010; 38:464-70

27. McCluskey SA, Karkouti K, Wijeysundera D, Minkovich L, Tait G, Beattie WS: Hyperchloremia after noncardiac surgery is independently associated with increased morbidity and mortality: A propensity-matched cohort study. Anesth Analg 2013; 117:412-21

28. Yunos NM, Bellomo R, Hegarty C, Story D, Ho L, Bailey M: Association between a chloride-liberal $v s$ chloride-restrictive intravenous fluid administration strategy and kidney injury in critically ill adults. JAMA 2012; 308:1566-72

29. O'Malley CM, Frumento RJ, Hardy MA, Benvenisty AI, Brentjens TE, Mercer JS, Bennett-Guerrero E: A randomized, double-blind comparison of lactated Ringer's solution and $0.9 \% \mathrm{NaCl}$ during renal transplantation. Anesth Analg 2005; 100:1518-24

30. Todd SR, Malinoski D, Muller PJ, Schreiber MA: Lactated Ringer's is superior to normal saline in the resuscitation of uncontrolled hemorrhagic shock. J Trauma 2007; 62:636-9

31. Young JB, Utter GH, Schermer CR, Galante JM, Phan HH, Yang Y, Anderson BA, Scherer LA: Saline versus Plasma-Lyte A in initial resuscitation of trauma patients: A randomized trial. Ann Surg 2014; 259:255-62

32. Prough DS, Bidani A: Hyperchloremic metabolic acidosis is a predictable consequence of intraoperative infusion of $0.9 \%$ saline. ANESTHESIOLOGY 1999; 90:1247-9

33. Scheingraber S, Rehm M, Sehmisch C, Finsterer U: Rapid saline infusion produces hyperchloremic acidosis in patients undergoing gynecologic surgery. ANESTHESIOLOGY 1999; 90:1265-70

34. Lee J, Iqbal S, Gursahaney A, Nouh T, Khwaja K: Medicine versus surgery/anesthesiology intensivists: A retrospective review and comparison of outcomes in a mixed medicalsurgical-trauma ICU. Can J Surg 2013; 56:275-9

35. Chung KK, Dubick MA: Building the case toward a definitive clinical trial: Saline versus Plasma-Lyte*. Crit Care Med 2014; 42:1009-10 